\title{
Endoscopic Endonasal Resection of Retrochiasmatic Craniopharyngioma with Fascia Lata Button and Nasoseptal Flap Reconstruction
}

\author{
Varun R. Kshettry ${ }^{1}$ Gurston Nyquist ${ }^{2}$ James J. Evans ${ }^{3}$
}

${ }^{1}$ Department of Neurological Surgery, Cleveland Clinic, Cleveland,

Address for correspondence Varun R. Kshettry, MD, Department of Ohio, United States

Neurological Surgery, Cleveland Clinic, 9500 Euclid Avenue, CA5-86,

2 Department of Otolaryngology, Thomas Jefferson University, Cleveland, OH 44195, United States (e-mail: kshettv@ccf.org).

Philadelphia, Pennsylvania, United States

${ }^{3}$ Department of Neurological Surgery, Thomas Jefferson University,

Philadelphia, Pennsylvania, United States

J Neurol Surg B 2018;79(suppl S2):S191-S193.

\begin{abstract}
Keywords

- endonasal

- surgical technique

- video

- suprasellar

- transinfundibular

Surgery for craniopharyngiomas can be challenging due to the involvement of multiple critical neurovascular structures. The expanded endoscopic endonasal approach can provide superior access to suprasellar craniopharyngiomas, particularly with retrochiasmatic extension and significant hypothalamic involvement. We describe the surgical technique used to treat a 30 -year-old patient who presented with 4 weeks of worsening vision, fatigue, and memory loss. His vision was counting fingers at 1 feet on the right and 20/800 on the left with a temporal hemianopsia. Laboratory evaluation demonstrated central hypoadrenalism, hypothyroidism, and hypogonadism. Imaging showed a large solid and cystic suprasellar mass. The transtubercular approach with removal of the lateral tubercular strut can provide wide bilateral access to the opticocarotid region. The superior intercavernous sinus must be coagulated and ligated. Initial arachnoid dissection is centered the midline, mobilizing the superior hypophyseal branches to the optic apparatus laterally. The cyst capsule is opened and care is taken to minimize spillage of cyst fluid into the subarachnoid space. Central debulking and then extracapsular dissection is performed under direct visualization using sharp dissection. Reconstruction of the dura is performed with an inlay/onlay fascia lata button that is held together with four sutures that hold the graft edges against the native dural edges. This is followed by vascularized nasoseptal flap
\end{abstract}

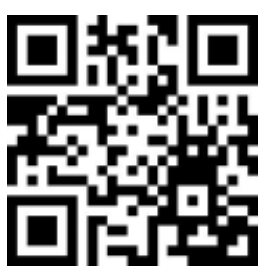

received

October 15, 2017

accepted

November 29, 2017

published online

January 9, 2018 www.thieme.com/skullbasevideos

www.thieme.com/jnlsbvideos
DOI https://doi.org/

10.1055/s-0037-1620260.

ISSN 2193-6331.
๑) 2018 Georg Thieme Verlag KG
Stuttgart · New York

License terms

(ㄷ) (i) $\ominus$ (8) 
reconstruction. No lumbar drain or nonabsorbable packing is required. The patient's vision had dramatic improvement and by 1 week postoperatively was 20/20 with full visual fields. Postoperative diabetes insipidus was managed with nasal desmopressin. Postoperative MRI demonstrated complete removal.

The link to the video can be found at: https://youtu.be/QQxCNUcq1qg.

\section{Conflict of Interest}

Dr. Evans reports personal fees from Stryker, other from Mizuho, outside the submitted work.

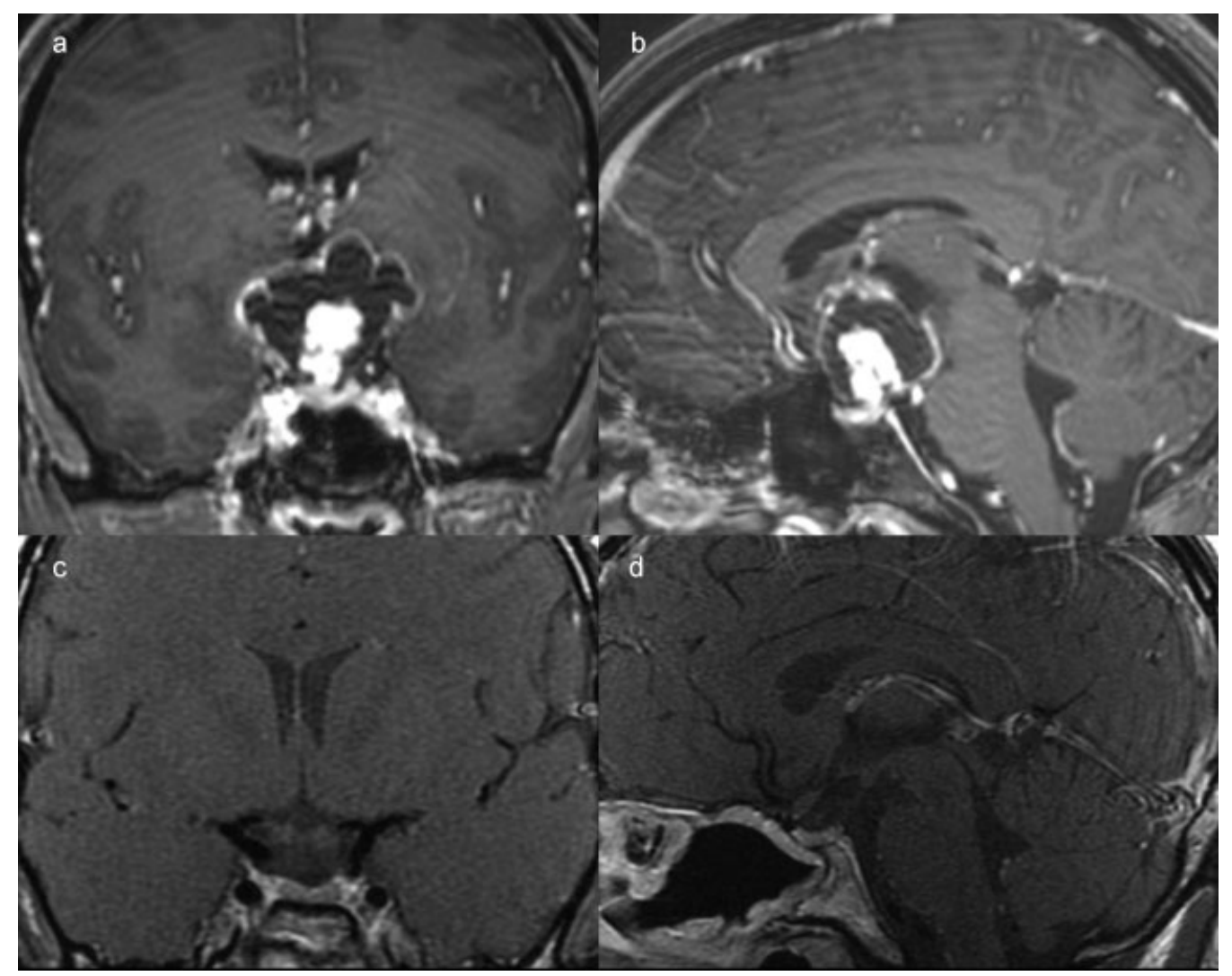

Fig. 1 Preoperative (a, b) T1 postgadolinium MRI views demonstrating a large cystic and solid suprasellar mass with compression of the hypothalamus bilaterally. Postoperative (c, d) T1 postgadolinium MRI demonstrating complete resection with healing of vascularized nasoseptal flap to the skull base. MRI, magnetic resonance imaging. 


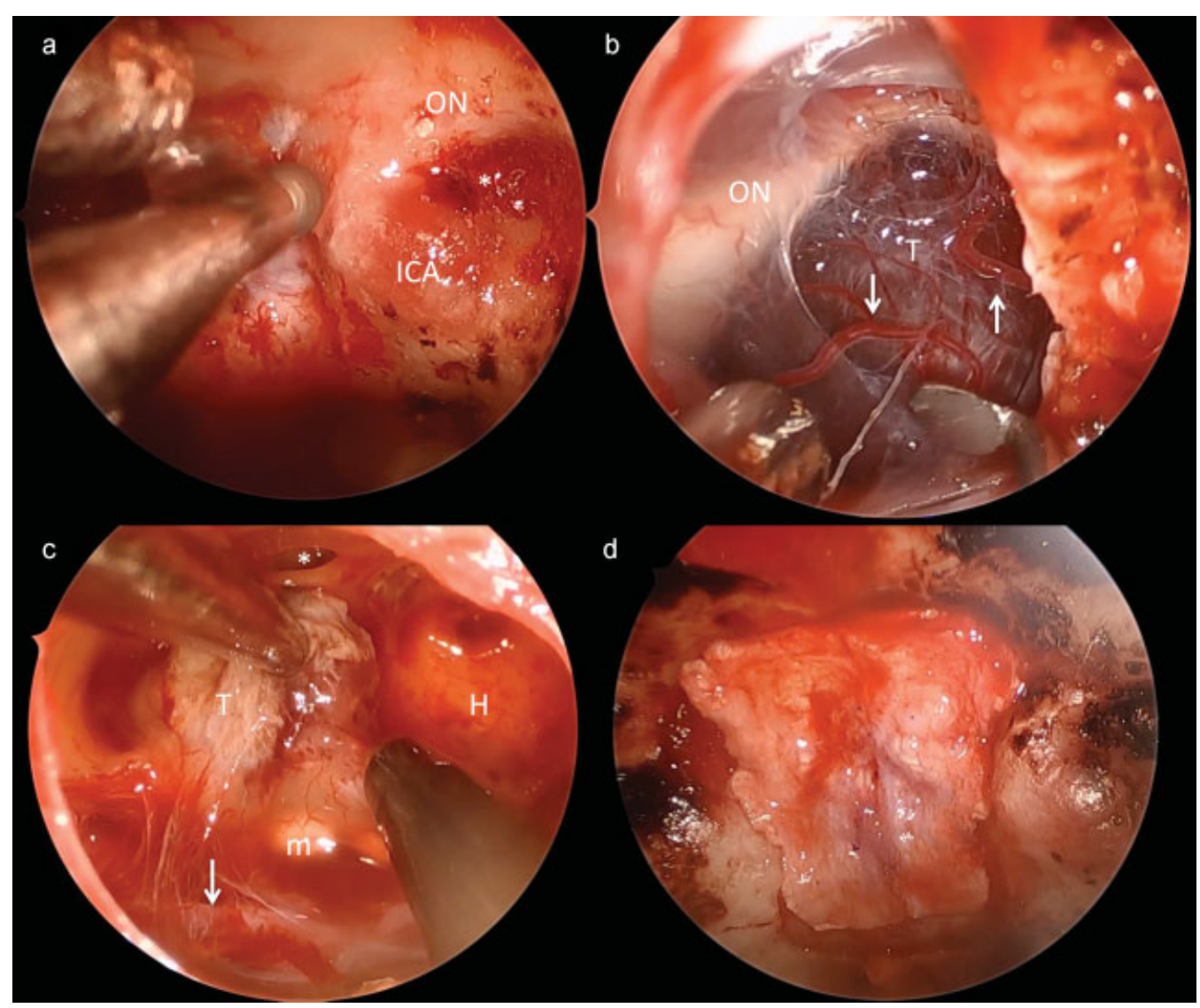

Fig. 2 Intraoperative views. (a) Adequate bony exposure includes drilling the lateral tubercular strut to open the opticocarotid region. (b) Initial arachnoidal dissection proceeds at the midline, mobilizing the superior hypophyseal arteries (arrows) laterally, preserving any branches going to the optic apparatus. (c) Final tumor $(\mathrm{T})$ resection, visualized is the hypothalamus $(\mathrm{H})$, third ventricular floor $\left({ }^{*}\right)$, mammillary bodies (m), and right posterior communicating artery (arrow). (d) Dural reconstruction performed with inlay/onlay fascia lata button graft with four sutures used to secure the two grafts together at the dural margins. ON, optic nerve; ICA, internal carotid artery; *lateral opticocarotid recess; T, tumor. 